\title{
El Neoliberalismo nace y muere en Chile: Um estudo de caso das políticas econômicas neoliberais na periferia do Sistema Internacional
}

\author{
Marina Moreno de Farias ${ }^{1}$ \\ Camila Gonzaga Seixas ${ }^{2}$
}

\section{Resumo}

O Chile é caracterizado como o primeiro país do Sistema Internacional a estabelecer o neoliberalismo enquanto projeto político e econômico. O objetivo principal deste artigo é analisar as consequências negativas dessas políticas nos âmbitos social, político e econômico, demonstrando como historicamente os índices macroeconômicos do país não são convertidos em direitos sociais, o que ocasionou, recentemente, diversas insurreições sociais. A teoria do Sistema Mundo auxiliará na compreensão acerca da dependência atribuída aos países periféricos, entendendo-se que os lucros e resultados econômicos positivos adquiridos nestes países são transferidos para os países do centro do sistemamundo capitalista. Assim, as práticas neoliberais empreendidas em países latinoamericanos, exemplificados aqui pelo Chile, demonstraram ser socialmente prejudiciais, além de reforçarem a posição hegemônica das potências do centro capitalista, status exercido sobretudo pelos Estados Unidos.

Palavras-chave: Neoliberalismo - América Latina - Sistema Mundo - Periferia Economia Política Internacional

\section{Abstract}

Chile is characterized as the first country in the International System to establish neoliberalism as a political and economic project. The main objective of this article is to analyze the negative consequences of these policies in the social, political and economic spheres, demonstrating how the country's macroeconomic rates are not transformed into social rights, which has recently caused several social upheavals. The World System Theory will help in the comprehension of the dependence attributed to peripheral countries, showing that the periphery is

\footnotetext{
${ }^{1}$ Graduanda em Relações Internacionais pelo Centro Universitário La Salle do Rio de Janeiro, pesquisadora em Migração, Fronteiras e Direitos Humanos, presidente do Diretório Acadêmico Sérgio Vieira de Mello, monitora em Teoria Política, redatora e editora política Revista Marginália.

${ }^{2}$ Graduanda em Relações Internacionais pelo Centro Universitário La Salle Rio de Janeiro.
} 
subjugated by the center in the international arena. Hence, the neoliberal practices undertaken in Latin American countries, represented in this work by Chile, proved to be socially harmful, in addition to reinforcing the hegemonic position of the powers of the capitalist center, a status exercised mainly by the United States.

Key-words: Neoliberalism - Latin America - World System - Periphery - International Political Economy

\section{Introdução}

As mudanças no setor previdenciário, a duplicação da inflação, o aumento nos preços tarifários, a privatização da educação, a destruição dos serviços públicos, a intensificação da pobreza e a liquidação dos direitos sociais em nome do capital financeiro são parte da conduta econômica habitual no Chile (LIRA, 2011) e em diversos países da América Latina. No que diz respeito ao Chile, tais políticas são fruto de um projeto neoliberal em curso desde a ditadura de Augusto Pinochet (19731990) e que, com efeito, resultou em uma crise de cunho sociopolítico. Esse cenário é um reflexo do projeto de neoliberalização das economias da periferia do Sistema Internacional que, ao reforçar a dependência destes países em relação às grandes potências, gera sobretudo o robusto fortalecimento da posição hegemônica dos países centrais.

Diante das insurreições sociais e populares que em 2019 ganharam força no Chile - país conhecido como "laboratório do projeto neoliberal" (BATISTA, 1994, p.26) - apresentamos no artigo o seguinte questionamento: como ocorreu tamanha crise em um país que era apresentado para o mundo como um modelo de sistema socioeconômico neoliberal? Além disso, questiona-se como o projeto neoliberal instaurado no Chile, um país da periferia do Sistema Internacional, impactou a economia, a política e a sociedade deste país, tornando-o dependente do centro?

Deste modo, esse artigo oferece uma análise da adoção do projeto neoliberal no Chile, aqui entendido enquanto representante da periferia do Sistema Internacional. A hipótese que orienta a pesquisa é que, na urgência de um golpe militar, houve um retrocesso das políticas e do modelo econômico em curso anteriormente, e que, anos após sua implementação, têm se mostrado falho e ineficaz. Diante da pesquisa realizada para este trabalho e da bibliografia mobilizada, compreendemos que os índices macroeconômicos e indicadores positivos não são convertidos em políticas sociais nas economias periféricas que adotaram o modelo 
neoliberal, mas concedidos ao capital financeiro e ao mercado internacional, com o crescente apoio das elites locais, gerando na periferia do Sistema Internacional uma contínua dependência aos atores hegemônicos do centro.

O objetivo geral deste trabalho é, portanto, entender como o viés desestatizante e de economia neoliberal implementado no Chile a partir da década de 1970 ocasionou uma crise social e política neste país da periferia do Sistema Internacional. Já os objetivos específicos são organizados em: (1) compreender o conceito de periferia do Sistema Internacional através da teoria do Sistema Mundo de Immanuel Wallerstein; (2) analisar como o neoliberalismo foi utilizado pelos Estados Unidos como mecanismo de manutenção de sua própria hegemonia, ao exportar o projeto econômico para a periferia do Sistema; e (3) correlacionar os impactos do neoliberalismo no Chile com as insurreições sociais de 2019 e um possível fim do paradigma neoliberal no país.

A base teórica utilizada como referência deste artigo é a teoria do Sistema Mundo formulada por Immanuel Wallerstein (1974), composta pelos conceitos de "centro", "periferia" e "semiperiferia". Ademais, é utilizada a teoria de Hegemonia Cultural e de Hegemonia, formuladas por Gramsci (1999) e Destradi (2010). Por fim, utiliza-se a teoria do Poder Global, proposta por José Luís Fiori (2009). Esta pesquisa é guiada pelo método dedutivo, comparativo e exploratório, (1) por partir de premissas gerais (cenário macro) como o funcionamento do Sistema Mundo e do neoliberalismo, visando entender as consequências deste último para a América Latina a partir do caso específico do Chile; (2) pela comparação de dois regimes políticos (pré-ditatorial e ditatorial) e seus respectivos projetos políticos (cenário micro); e (3) exploratório porque busca identificar causas e padrões de comportamento para os fenômenos estudados. Os dados são fundamentados pela pesquisa documental e revisão bibliográfica de fontes primárias (documentos oficiais) e secundárias (artigos acadêmicos, livros e textos jornalísticos).

O presente artigo está estruturado em quatro seções. A primeira seção visa explicar o referencial teórico utilizado no trabalho, a partir de autores da Economia Política Internacional e de áreas correlatas, além de alguns conceitos essenciais para a compreensão do tema. A segunda seção pretende explicar não apenas a ideia econômica do neoliberalismo, mas o projeto político imbricado nele, buscando analisar também o projeto neoliberal enquanto estratégia de poder do centro. A terceira abordará uma análise de elementos históricos do Chile com os antagonismos entre o governo de Salvador Allende e a Ditadura de Pinochet na década de 1970. Isso posto, visamos explicar como os Estados Unidos, durante a Guerra Fria, inseriram sua ideologia neoliberal na América Latina, por meio da 
cooperação para que diversas ditaduras militares fossem instauradas na região. Apresentamos ainda um estudo de caso das consequências do empreendimento neoliberal na periferia mundial. Finalmente, a quarta seção abarca um apanhado dos protestos sociais ocorridos no Chile em 2019, buscando traçar uma contextualização histórica dos eventos, para entender como se deu a crise e o descontentamento com o neoliberalismo e observar se esta pode representar o fim do projeto neoliberal neste país da periferia do Sistema Internacional.

\section{Sistema-Mundo, Hegemonia e Poder Global: uma discussão teórica} Pretendemos conduzir este trabalho a partir da teoria do Sistema Mundo, elaborada por Immanuel Wallerstein, sociólogo norte-americano. Segundo o autor, o Sistema Internacional - o 'mundo' nos âmbitos das relações políticas e das disputas de poder - é dividido em três estamentos hierárquicos: centro, periferia e semi-periferia (WALLERSTEIN, 1974). Essa divisão, constitutiva da própria gênese do capitalismo ocidental, garante que cada país do sistema cumpra uma função na ordem de produção do capitalismo global. É importante salientar que não há igualdade de unidades dentro desse sistema, ou seja, tais estamentos são assimétricos em suas capacidades de poder (sejam estas materiais ou subjetivas, i.e. hard power ou soft power).

Nesse sentido, os países do centro fabricam os bens e serviços de alto valor agregado, enquanto os da periferia produzem os bens e serviços do setor primário (commodities e matérias-primas), voltados sobremaneira à exportação para os países centrais. A semiperiferia, por sua vez, desempenha um papel intermediário, comportando-se por vezes como centro para a periferia, por vezes como periferia para os Estados centrais (MARTINS, 2015). Uma síntese dos elementos constitutivos de cada uma dessas unidades hierárquicas do Sistema Mundo pode ser observada no Quadro 1. 
Quadro 1: Aspectos definidores do Sistema-Mundo

\begin{tabular}{|l|l|l|l|}
\hline Nível & Aspecto Econômico & Aspecto Político & Aspecto Cultural \\
\hline Centro & $\begin{array}{l}\text { Países com produção de alto valor } \\
\text { agregado tecnologico; produtor e } \\
\text { exportador de tecnologia; mão de } \\
\text { obra especializada }\end{array}$ & $\begin{array}{l}\text { Paises que são Estados } \\
\text { fortes, tendo a capacidade } \\
\text { de ampliar seu domínio } \\
\text { para além de suas fronteiras }\end{array}$ & $\begin{array}{l}\text { Possuem forte identidade } \\
\text { nacional e ampliam sua } \\
\text { identicade como referencial } \\
\text { para além das fronteiras }\end{array}$ \\
\hline $\begin{array}{l}\text { Semi- } \\
\text { periferia }\end{array}$ & $\begin{array}{l}\text { Países de industrialização de baixo } \\
\text { valor tecnológico agregado; não } \\
\text { produz tecnologia, mas a absorve; } \\
\text { mão de obra semi-especializada e } \\
\text { não especializada }\end{array}$ & $\begin{array}{l}\text { Estados que têm o controle } \\
\text { de sua política interna, mas } \\
\text { não exercem influência } \\
\text { externa }\end{array}$ & $\begin{array}{l}\text { Possuem identidade cultural } \\
\text { e nacional média }\end{array}$ \\
\hline Periferia & $\begin{array}{l}\text { Países que produzem produtos } \\
\text { primários apenas; mão de obra não } \\
\text { especializada }\end{array}$ & $\begin{array}{l}\text { Estados que nem possuem } \\
\text { o controle da sua politica } \\
\text { interna, nem exercem } \\
\text { influência externa }\end{array}$ & $\begin{array}{l}\text { Não possuem identidade } \\
\text { nacional ou é fragmentada, } \\
\text { prevalecendo identidades } \\
\text { étnica ou religiosa }\end{array}$ \\
\hline
\end{tabular}

Fonte: (MARTINS, 2015, p.100).

Diante disso, o argumento essencial aqui é que o padrão desigual dessas relações de poder cria uma dependência entre a periferia e o centro, neste trabalho representados por Chile e Estados Unidos, respectivamente. Uma das formas com que se dá essas relações de dependência da periferia ao centro é a exportação de commodities e matérias-primas de baixo valor agregado para o centro, ao considerar que no capitalismo industrial ${ }^{3}$ os países periféricos não atingiram o mesmo padrão de desenvolvimento econômico e industrialização dos países do centro (DOS SANTOS, 2000). Ao considerarmos processos como a globalização neoliberal e a financeirização do capital, tal dependência também pode se apresentar na forma de empréstimos com organismos internacionais, além de renegociações de dívidas com a condicionalidade de adoção de um receituário neoliberal, como ocorreu nos anos 1980 e 1990 em países da periferia mundial (AYERBE, 2002).

Faz-se necessário conceituar também, de acordo com a teoria do Sistema Mundo, mas também com outros referenciais teóricos da Economia Política Internacional e das Relações Internacionais, a noção de hegemonia, utilizada aqui como sinônimo de potência hegemônica. Em resumo, hegemonia é o exercício do poder dominante, do centro sobre a periferia global, seja pelas capacidades materiais coercitivas, seja por narrativas culturais i

\footnotetext{
${ }^{3}$ Fase do sistema capitalista que surgiu durante um processo de revoluções políticas e tecnológicas na Europa, criando o modo de produção capitalista das máquinas e fábricas como as conhecemos hoje (MARX, 1968).
} 
ideológicas, de difundir seus valores na comunidade internacional - o soft power ${ }^{4}$ (DESTRADI, 2010; GARCIA, 2010).

Assim, transpondo o conceito de hegemonia cultural de Gramsci (1999) para uma análise do Sistema Mundo, podemos sustentar que a hegemonia não se dá apenas de maneira coercitiva (i.e. pelo uso da força), mas também pela via do consenso - quando a periferia adere aos discursos, normas e valores do centro, pois estes são projetados como valores universais a partir do empreendimento do poder brando. De acordo com Cox,

\begin{abstract}
Historicamente, para se tornar hegemônico, um Estado teria de fundar e proteger uma ordem mundial que fosse universal em termos de concepção, isto é, uma ordem com que um Estado não explore outros Estados diretamente, mas na qual a maioria desses (ou pelo menos aqueles ao alcance da hegemonia) possa considerá-la compatível com seus interesses. Essa ordem dificilmente poderia ser concebida apenas em termos interessados, pois isso provavelmente traria para primeiro plano os interesses opostos dos Estados. [...] As instituições econômicas e sociais, a cultura e a tecnologia associadas a essa hegemonia nacional tornam-se modelos a serem imitados no exterior. Essa hegemonia expansiva é imposta aos países mais periféricos como uma revolução passiva. Esses países não passaram pela mesma revolução social completa, nem têm suas economias desenvolvidas da mesma forma, mas procuram incorporar elementos do modelo hegemônico sem que as antigas estruturas de poder sejam afetadas (COX, 2007, p.118).
\end{abstract}

Autores como Triepel (1983) consideram a hegemonia uma forma de execução do poder situado em um nível intermediário, mas contínuo, entre influência e dominação. Já Destradi (2010), considera que a potência hegemônica opera de maneira a combinar incentivos materiais e instrumentos de poder "ideacionais" (alterando e/ou reformulando normas nos estados subordinados) para obter consenso desses Estados (periferia/semiperiferia).

Em suma, entendemos, a partir dos autores e teorias supracitados, que é fundamental compreender a hegemonia como um exercício do poder que se dá não somente pela dominação e pelas capacidades materiais concretas dos Estados, mas também por fatores ideológicos, normativos e culturais. Assim, de acordo com a formulação de hegemonia em Gramsci e sua transposição para as Relações Internacionais por Cox (1983), o sentido mais abrangente de hegemonia seria "uma 'expansão para o exterior' de uma hegemonia nacional estabelecida por uma classe dominante [...] Por meio dessa expansão, é formada uma ordem mundial baseada na hegemonia de um Estado sobre os demais" (PEREIRA, 2011, p. 240). Destaca-se, ainda, a função primordial das instituições internacionais para universalizar os

\footnotetext{
${ }^{4}$ Soft Power é o poder brando, ou o poder de convencimento, sendo exercido a partir da habilidade de influência não-coercitiva de um Estado, enquanto o Hard Power é um conceito do poder que se dá através do empreendimento de recursos militares e econômicos de modo coercitivo (NYE, 2002).
} 
interesses particulares das classes dominantes no sistema mundo capitalista (COX in GILL,1983; PEREIRA, 2011).

Observando o Quadro 1, vale mencionar que a posição de centro não é estática, mas marcada por disputas de poder em seu entorno (WALLERSTEIN, 1964; FIORI, 2009). Diante disso, a hegemonia não é posição fixa, mas competição constante por poder. Buscando uma relação com a Teoria do Poder Global pertinente à análise, Fiori (2009) diz que não se pode caracterizar poder como acúmulo, somente como exercício e, portanto, reprodução constante de capacidades e fluxo de poder sobre outros. Essa ótica nos permite inferir que a manutenção do poder que confere o status ao Estado que atua enquanto poder hegemônico só é conquistada através da busca incessante por poder; esta busca, mesmo que não ativamente, reforça o subdesenvolvimento na periferia do Sistema Internacional, tendo em vista que o poder precisa ser exercido sobre outros (FIORI, 2009).

Dentro desta análise, entendemos que este fluxo de capacidades mobilizado pelo ator hegemônico (hegemon) se dá a partir do enquadramento das economias da periferia, por meio de pressões externas, de concessão de empréstimos e renegociação de dívidas cotadas em dólar, investimentos externos diretos (IED) e pressões diplomáticas, fazendo com que haja uma manutenção e uma acentuação do subdesenvolvimento dos países em desenvolvimento (BATISTA, 1994; MACHADO, 1999).Nesse sentido, podemos compreender por que a manutenção de tais disposições assimétricas dentro do ordenamento do Sistema Internacional são do interesse do centro do capitalismo mundial (WALLERSTEIN,1994). O que pretendemos com o decorrer do trabalho é esclarecer como tal manutenção de posição dentro do capitalismo mundial é fortalecida pelo empreendimento do neoliberalismo na periferia do Sistema.

\section{O Neoliberalismo enquanto conceito econômico e político}

Nesta seção, pretendemos fazer uma análise do neoliberalismo como entendemos que ele foi construído na economia política internacional: um mecanismo de poder e dominação. É observável que o empreendimento do neoliberalismo na periferia do Sistema Internacional é feito de forma a fortalecer o centro, que com recursos materiais e ideológicos (Hard Power e Soft Power), subjuga e coage a periferia.

Enquanto conceito econômico, o neoliberalismo surge como aprofundamento do liberalismo clássico fundamentado na doutrina do laissez-faire. Suas características principais envolvem a privatização da esfera pública, a liberalização do comércio exterior e a especulação financeira, reduzindo ao mínimo o poder de intervenção estatal sobre a economia, em favorecimento a um suposto poder de autorregulação do mercado (BATISTA, 1994; NASCIMENTO, 2008). É importante mencionar que o empreendimento neoliberal 
propõe um esvaziamento da política e da organização social, criando assim um ambiente onde é permitido somente a atuação imprecisa do mercado, o direito à propriedade, a competitividade e a meritocracia. Assim:

\begin{abstract}
Nesses espaços da racionalidade, o mercado é tornado tirânico e o Estado tende a ser impotente. Tudo é disposto para que os fluxos hegemônicos corram livremente, destruindo e subordinando os demais fluxos. Por isso, também, o Estado deve ser enfraquecido, para deixar campo livre (e desimpedido) à ação soberana do mercado.
\end{abstract}

(SANTOS, 2001, p. 33-34).

Enquanto estabelecimento de políticas concretas, o neoliberalismo propõe privatizações em massa, o que com efeito entrega os serviços e bens públicos ao livre mercado de concorrência capitalista e gera a mercantilização e financeirização crescentes dos serviços sociais, como a saúde, o transporte, a previdência e a educação (FLEURY, 2004).

Dentro do projeto neoliberal, foi estabelecido um aumento da renda da classe capitalista, na medida em que se começou a pagar salários muito robustos para as classes altas, além dos ônus das taxas de juros dos bancos que beneficiam os emprestadores (BRESSER-PEREIRA, 2010). Como exemplo rigoroso dessas características, podemos citar as políticas adotadas no pós-Crise de $2008^{5}$, momento em que o Estado atuou para salvaguardar os bancos nos Estados Unidos, mesmo que no plano discursivo o país seguisse atuando como bastião do neoliberalismo e advogando em favor do livre-mercado e do nãointervencionismo estatal (BRESSER-PEREIRA, 2010; DUMÉNIL; LÉVY, 2011).

Nesse sentido, se o liberalismo se calca na premissa de que o governo e suas motivações políticas não devem interferir na economia, então o neoliberalismo - mesmo que de forma oculta - empreende uma lógica intervencionista, de forma que, na direção contrária à proteção da população e da promoção do bem-estar social, o Estado intervém gerando mais riqueza às grandes empresas, corporações, bancos e às classes mais altas da sociedade. Assim, "o neoliberalismo não se constitui como princípio limitador, mas como fundador do Estado" (FOUCAULT, 2008, p. 300), aumentando a financeirização, a presença de capital especulativo ${ }^{6}$ e impactando diretamente na acumulação da sociedade não financeira.

\footnotetext{
${ }^{5}$ As medidas adotadas assim que irrompeu a crise incluíam: (1) aumento da liquidez por meio da redução da taxa básica de juros; (2) resgate dos principais bancos; (3) adoção de políticas fiscais expansionistas e (4) regulação do sistema financeiro (BRESSER-PEREIRA, 2010, p.66-67).

${ }^{6} \mathrm{O}$ capital especulativo é aquele investido visando a obtenção rápida de lucro, sem oferecer ganhos para a economia, porque o lucro não é gerado por meio do trabalho ou produção, e sim a partir de operações de compra e venda de moedas ou ativos financeiros (ações ou outros títulos). Seus investimentos não geram empregos, nem são destinados à compra de matérias-primas, não aumentam a oferta de produtos no mercado, não movimentam a economia como um todo (PAULO, 2000).
} 
Ainda segundo Foucault (2008, p. 163), enquanto no liberalismo clássico a concorrência era pensada como atributo natural do laissez faire do mercado, no neoliberalismo ela aparece "como forma organizadora do mercado". O lugar da concorrência na teoria neoliberal é então paradoxal: é necessária enquanto elemento organizacional da economia, mas esse processo não é intrínseco à natureza das relações econômicas e comerciais, e sim fruto da atuação do Estado que agora precisa governar para o mercado (FOUCAULT, 2008).

Figura 1: Participação na riqueza do 1\% mais rico nos Estados Unidos, entre 1913 e 2006.

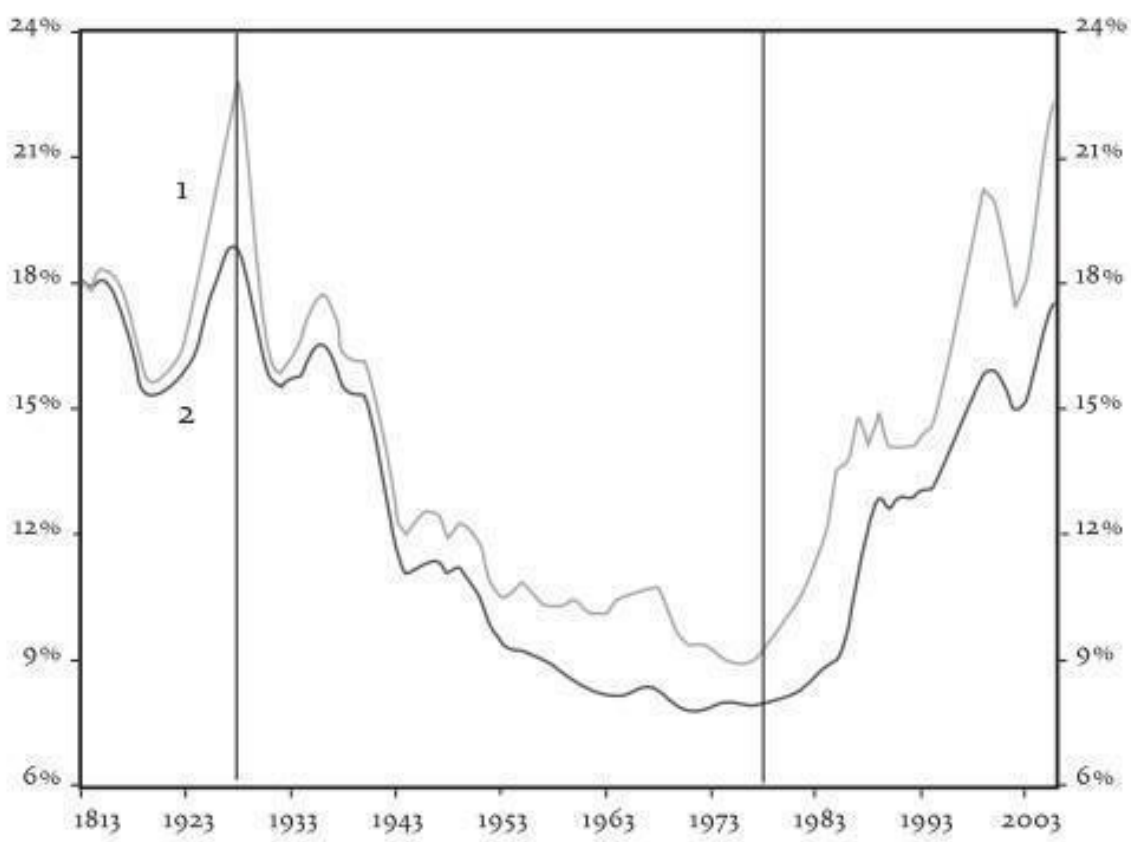

Fonte: (PALMA, 2009, p. 836).

Como demonstra a Figura 1, o neoliberalismo gera uma forte concentração de renda internamente: "se considerarmos apenas o 1\% mais rico nos Estados Unidos, em 1930 controlava $23 \%$ da renda disponível total; em 1980, no contexto dos trinta anos dourados do capitalismo, sua participação caíra para 9\%; mas, em 2007, retornara aos 23\%" (BRESSERPEREIRA, 2010). Nesse sentido, Duménil e Lévy (2007, p. 1) acrescentam:

[...] A decisão, tomada em 1979, pela Reserva Federal dos Estados Unidos (EUA), de aumentar as taxas de juros até onde fosse necessário para acabar com a inflação, pode ser considerada como um acontecimento que testemunhou uma mudança maior na dinâmica do capitalismo [...] Entre a Segunda Guerra Mundial e o começo dos anos 1970, o 1\% mais rico das famílias dos EUA tinha mais de $30 \%$ da riqueza total do país; durante a primeira metade dos anos 1970 , essa percentagem tinha caído para $22 \% .5$ O neoliberalismo foi um golpe político cujo objetivo era a restauração desses privilégios. A esse respeito, foi um grande sucesso. 
Já no cenário internacional, é preciso destacar a atuação do neoliberalismo dentro da globalização - apogeu do sistema capitalista - tendo em vista a produção de bens e de serviços estruturados em uma teia de financeirização, especulação, lucro imediato, altas taxas de juros, enriquecimento de bancos, e negligência à classe trabalhadora em nível global (VALOIS, 2018; IBARRA, 2011). Nesse sentido, é crucial lembrar do Consenso de Washington como peça-chave na consolidação do projeto neoliberal para a periferia mundial. O projeto foi formulado em 1989 por economistas dos Estados Unidos e de instituições financeiras internacionais, se tornando diretriz econômica central para a atuação do Banco Mundial, do Departamento do Tesouro dos Estados Unidos e do Fundo Monetário Internacional (FMI) em seus esforços reestruturar os países em desenvolvimento (BERNALMEZA,1998; BATISTA,1994). As medidas incluíam disciplina fiscal, reorientação do gasto público, taxa de juros determinada pelo mercado, liberalização do comércio e políticas de privatizações (BANCO MUNDIAL, 1990). Tratava-se de um esforço para reunir de maneira efetiva as políticas neoliberais já recomendadas e transformá-las em um projeto político para a periferia mundial.

Alguns anos antes da formulação do Consenso de Washington, houve 0 empreendimento destas mesmas políticas econômicas por Margareth Thatcher (1979-1990), primeira-ministra da Inglaterra, e Ronald Reagan (1981-1989), presidente dos Estados Unidos. Além de adotarem o modelo neoliberal em seus próprios países, Thatcher e Reagan estabeleceram precedentes para a sua imposição rumo à periferia do Sistema-Mundo: 0 discurso do "there's no alternative"7 cada vez mais coagia os países periféricos a adotarem o modelo neoliberal. Nesse sentido, os países do centro passaram a impor o receituário neoliberal como condição necessária para políticas de cooperação financeira, cooperação internacional para o desenvolvimento (CID), investimentos externos diretos (IEDs) e participação diplomática em grupos de livre-comércio ou de coordenação política. Os países que precisassem de empréstimos do Fundo Monetário Internacional, renegociar suas dívidas ou entrar em acordos comerciais bilaterais e multilaterais precisavam também adotar em seus países o modelo imposto pelo neoliberalismo (BATISTA, 1994).

Assim, o Consenso de Washington, como evento que consolidou o neoliberalismo e sua aplicação na América Latina, evidencia a insensata abertura das economias latinoamericanas através de um processo de pressão econômica direta e imposição de um consenso de ideias, narrativas e aplicação de políticas concretas tidas como necessárias ao

\footnotetext{
7 "There is no alternative" foi o slogan político de Margareth Thatcher enquanto primeira-ministra da Inglaterra (1979-1990), se referindo ao fato de que não havia alternativa às leis do mercado, ao capitalismo, ao neoliberalismo e a própria globalização não apenas para a população inglesa, mas para a população do mundo onde o neoliberalismo é exportado (ANTUNES, 2004).
} 
desenvolvimento (NASCIMENTO, 2008). Desse modo, o Consenso estabelece os marcos do que Sotelo (2004, p. 97-99) caracterizou como "nueva formación económica social neoliberal capitalista dependiente" e que Osório (2004) afirmou como um novo padrão exportador latinoamericano. Trata-se de um aprofundamento do padrão de dependência da América Latina, a partir de sua inserção na nova fase do capitalismo financeiro, dentro da lógica da periferia enquanto exportador de bens primários. Contra esforços anteriores de industrialização nacional, reforça-se a inserção dos países latino-americanos na economia global a partir da importação de produtos de alto valor agregado e exportação de bens e serviços de baixo valor agregado, com uma maior abertura ao capital externo (AMARAL, 2006). Destaca-se ainda uma intensificação da dependência no setor financeiro:

\begin{abstract}
Esta nova fase da dependência e do capitalismo em geral distingue-se das anteriores por conta de uma característica que lhe é peculiar: a forte "generalização do movimento especulativo do capital" [...] ou, conforme se convencionou chamar na literatura recente, a presença de um intenso processo de financeirização da economia, que se exacerba ao ponto de tornar a lógica especulativa predominante sobre a lógica produtiva, isto é, ao ponto de o capital produtivo se subordinar ao capital financeiro [...] nos marcos do capitalismo atual, a dependência se estabelece mediante um intenso aprofundamento da vulnerabilidade externa dos países periféricos frente aos centrais, exatamente em função da predominância do capital fictício em suas estruturas. Este é o emblema, o definidor, a característica ou condição estruturante desta nova fase da dependência, de modo que podemos identificar a condição dependente de um país a partir de seus níveis de vulnerabilidade externa (AMARAL, 2006, p. 57).
\end{abstract}

Assim, a renegociação das dívidas com as instituições financeiras internacionais, a partir da adoção do pacote neoliberal, abertura econômica, desregulamentação e toda a estrutura de liberalização, aumenta desigualdades estruturais, a dependência das economias nacionais latino-americanas ao centro do capitalismo e reforça a hegemonia financeira dos EUA (JEFFERSON et al., 2008; BATISTA, 1994).

\title{
3. O neoliberalismo no Chile
}

\subsection{0 cenário internacional e como o Chile se tornou o "laboratório do neoliberalismo"}

No caso do Chile, a aplicação do modelo neoliberal se deu décadas antes de sua implementação no restante da América Latina. Teve suas bases na imposição de um regime ditatorial autoritário apoiado pelos EUA no âmbito da Operação Condor, criada pelo Departamento de Estado dos EUA - em parceria com a Central Intelligence Agency (CIA) a para coordenar as ditaduras instauradas no Cone Sul (Argentina, Bolívia, Brasil, Chile, Paraguai e Uruguai) como estratégia de contra-insurgência anticomunista na região 
(AYERBE, 2002). No caso do Chile, a Operação Condor deu endosso à ditadura instaurada com o golpe 1973, regime que deu início à implementação do modelo neoliberal como projeto experimental. Por essa razão, a alcunha de "laboratório do neoliberalismo" foi atribuída ao país (BARDER, 2013). Assim:

A implementação experimental da ortodoxia econômica - a desregulamentação do poder estatal, a financeirização ou a prática desenfreada dos mercados financeiros e comerciais, a privatização e a destruição de formas de solidariedade social como os sindicatos estabeleceu o Chile como o primeiro laboratório neoliberal em grande escala. [...] O que foi significativo neste caso foi que a experiência neoliberal ocorreu na sequência do golpe de Estado influenciado pelos americanos pelo general Augusto Pinochet em 11 de setembro de 1973. A eleição do socialista Salvador Allende em 1970 foi julgada pela administração Nixon como uma grave ameaça aos interesses estratégicos e corporativos americanos no hemisfério ocidental. $\mathrm{O}$ assessor de segurança nacional Henry Kissinger argumentou em uma reunião do Conselho de Segurança Nacional [NSC] que o programa de Allende representaria algumas ameaças muito sérias aos nossos interesses e posição no hemisfério e afetaria os desenvolvimentos e nossas relações com eles em outras partes do mundo (BARDER, 2013, p.107 tradução livre).

Assim, o autoritarismo da ditadura instaurada por Pinochet - com apoio estadunidense contra o socialismo democrático de Allende - anda lado a lado com a implementação do neoliberalismo no país (BARDER, 2013; CORVALÁN, 2003). Entre os resultados, a ditadura de Pinochet levou a prisão de mais de 13.000 pessoas tidas como "marxistas subversivas", dentro do processo de ruptura com o regime democrático que os Chicago boys ${ }^{8}$ viam como obstáculo para a adoção do "livre-mercado" (VALDÉZ, 1995). Com efeito, se analisarmos criticamente, o projeto neoliberal não é somente um espectro de medidas econômicas, mas sobretudo um instrumento de configuração de poder do centro, neste caso representado pelos Estados Unidos, para a manutenção e ampliação de seu próprio poder financeiro, e portanto, posição enquanto hegemon do Sistema Internacional (BELLUZZO; TAVARES, 1998).

Quanto a seus impactos na periferia, notadamente no Chile, é possível estabelecer uma série de questionamentos. Em linhas gerais, o país é considerado um modelo de aplicação do modelo neoliberal, por seus índices econômicos e sociais altos se comparados aos demais países da América Latina. Contudo, é importante lembrar que as bases para a ascensão econômica do Chile foram estabelecidas ainda na década de 1970, por medidas instauradas pelo governo socialista democráticos de Salvador Allende, tais como a reforma

\footnotetext{
8 Termo utilizado para se referir a economistas latino-americanos que estudaram no Departamento de Economia da Universidade de Chicago, nos Estados Unidos, e retornaram para a América Latina com os ideias do neoliberalismo, tomando-os como proposição para implementação de uma nova agenda econômica na região. Esse departamento à época estava sob a direção de Milton Friedman, que por sua vez adotava os ensinamentos de Friedrich Hayek, ambos autores percursores da teoria neoliberal na economia.
} 
agrária e incremento do desenvolvimento industrial, revertidos na melhoria das condições de vida da classe trabalhadora chilena (DAVIS, 1990; LIRA, 2011).

Tais medidas desagradaram instituições internacionais comprometidas com o centro. O FMI, por exemplo, engessou seus empréstimos para o país, fazendo-o perder credibilidade internacional e gerando assim um decréscimo substancial nos investimentos externos (LIRA, 2011). A isso, soma-se o elemento de hard power, representado no apoio dos EUA ao golpe que depôs Allende em 1973, protagonizado pelo General do Exército Augusto Pinochet, pelas Forças Armadas chilenas e por setores da direita como o empresariado nacional e estrangeiro.

A Ditadura Militar instaurada no Chile, que durou até os anos 1990, corresponde à ascensão do soft power dos Estados Unidos e à projeção de atuação internacional dos economistas da Escola de Economia de Chicago (intitulados Chicago Boys), que enxergaram uma oportunidade para o experimento neoliberal no país andino da América Latina (BARDER, 2013; CORVALÁN, 2003;). Assim, as relativas liberdades econômicas que compunham o projeto neoliberal, vinham também com a repressão agressiva das liberdades civis, perpetrada pelo Estado ditatorial chileno contra movimentos sociais e sindicais (VÁLDEZ,1995).

Entre as medidas tomadas durante o governo ditatorial de Pinochet, sob influência dos Chicago Boys, estavam a liberalização comercial e financeira, a abertura indiscriminada para fluxos internacionais de capital, o enxugamento do setor público, privatização de empresas, reintegração de posse de terras que haviam sido distribuídas na reforma agrária e supressão de direitos sindicais (MOREL, 2008; VASCONCELOS, 2017). Até mesmo serviços públicos essenciais, como a previdência social, os serviços de saúde e a educação, foram privatizados durante o regime ditatorial de Pinochet (WISECARVER, 1992). Vale salientar que as medidas de desestatização foram iniciadas em meio a recessão econômica, não havendo grande número de potenciais compradores, o que culminou na concentração de propriedade das ações nas mãos de poucos acionistas majoritários (MOREL, 2008).

Contudo, mesmo com estas reformas, a economia não se estabilizou, de modo que a inflação se manteve congelada em 300\% nos anos de 1974 e 1975 (FFRENCH-DAVIS, 2008). Em 1975, houve a retração de $12 \%$ do PIB nacional, com queda da participação industrial reduzida em 5\% entre 1970 e 1981, gerando uma forte depressão econômica (FFRENCH-DAVIS, 2008). Após tantas resoluções sem êxito, os Chicago Boys insistiram mais uma vez no princípio de que conseguiriam diminuir a inflação ao reduzir a influência do Estado na economia (FRENCH-DAVIS,2008). Houve ainda a retirada de tarifas dos produtos importados, levando à dissolução da incipiente produção industrial nacional (LIRA, 2011).

Assim, o Chile foi percursos também do processo de desindustrialização que na década de 1990, sob a égide neoliberal no Sistema Internacional, iria atravessar os demais 
países da América Latina (MONIZ-BANDEIRA, 2010; OREIRO; FEIJÓ, 2010 ROWTHORN; RAMASWANY, 1999). No caso do Chile, a desindustrialização foi acompanhada de uma reprimarização na pauta da exportação, com consequente intensificação da dependência com relação aos países do centro do Sistema Internacional.

\subsection{Um balanço dos resultados econômicos, políticos e sociais do projeto neoliberal no Chile}

Nos dias atuais, o Chile é consagrado como uma das economias mais organizadas do Sistema Internacional, sendo avaliado positivamente em 2019 no Relatório de Desenvolvimento Humano da ONU - seu IDH chegou a 0,847 - e liderando o ranking de desenvolvimento econômico entre os países da América do Sul (PNUD, 2019). Com essas vantagens, o país sul-americano foi aceito em 2010 na Organização para a Cooperação e Desenvolvimento Econômico (OCDE), gerando uma relevância considerável para o país na economia internacional.

Entretanto, esses números mascaram profundos problemas sociais, políticos e econômicos presentes no país. O alto índice de crescimento econômico demonstrado por indicadores como PIB e renda per capita não demonstram sucesso das políticas neoliberais no que diz respeito ao desenvolvimento interno, riqueza nacional ou igualdade socioeconômica no país. Boa parte da riqueza produzida no Chile desde a implementação do modelo neoliberal foi acumulada por representantes do setor privado da sociedade chilena e das elites que o dominam (ENCINA, 2015).

Trazendo essa discussão para um cenário mais contemporâneo, segundo Relatório do Banco Central (2019), em uma renda familiar média no Chile em 2019, 73\% dos recursos foram direcionados a pagar dívidas e 33,5\% para pagar gastos com a saúde. Esses dados contribuem para a visão na qual para se viver no Chile com dignidade e acesso ao transporte, saúde e educação é preciso contar com os créditos bancários. Isto posto, estimativas explicitam que 11 dos 18 milhões de chilenos possuíam dívidas em 2019 (FUNDAÇÃO SOL, 2019).

Além disso, um estudo da Universidade Diego Portales aponta que o transporte no Chile é o nono mais caro do mundo (EL PAÍS, 2019). O país também foi eleito em 2019 o sétimo mais desigual do mundo, de acordo com o Coeficiente de Gini ${ }^{9}$. Este fator contribuiu para a criação do Crédito com garantia Estatal (CAE), sistema que financia o acesso dos estudantes ao nível superior de ensino, culminando na dívida estudantil exacerbada entre 2006 e 2018: um valor total de 7.657 milhões de dólares, que segue crescendo até os dias

\footnotetext{
${ }^{9}$ Instrumento estatístico para medir a desigualdade de uma distribuição, de forma a analisar a concentração de renda. Os valores são representados entre 0 e 1 : quanto mais perto de zero menor é a desigualdade social, quanto mais próximo de 1 , maior é a desigualdade.
} 
atuais. Apenas três bancos recebem 90\% dos empréstimos: Scotiabank, Estado e Itaú, corroborando para a acumulação de renda das classes dominantes (KREMERMAN; PÁEZ; SÁEZ, 2020).

De acordo com a última edição do relatório Panorama Social da América Latina elaborado pela Comissão Econômica para a América Latina e o Caribe (CEPAL), em 2017, a parcela de $1 \%$ mais rica da população chilena concentrava $26,5 \%$ da riqueza do país, enquanto $50 \%$ das famílias de baixa renda representavam apenas $2,1 \%$ da riqueza líquida. Desse modo, com base no exemplo chileno, entendemos que o projeto neoliberal estabelecido na América Latina ${ }^{10}$ desenvolve a economia em prol do mercado global, culminando na supressão do protecionismo, da política industrial, dos direitos laborais e ampliando as privatizações, abertura de fronteira, desregulamentação e flexibilização das normas de proteção trabalhista.

Tais processos estão diretamente relacionados a uma concentração de poder econômico e político no centro do Sistema Mundo capitalista, onde a força de trabalho vinda da periferia com salários ínfimos gera mobilidade de capital indo em direção aos países centrais, enquanto a periferia regride às exportações de bens primários e de commodities. No Chile, os índices reverberam uma problemática estagnação na produção: "em 1990 a soma das exportações de recursos primários e baseados em recursos naturais representou $89 \%$ do total das exportações do Chile, enquanto em 2014 era responsável por exatamente o mesmo (89\%)" (NETO, 2016, p. 19).

Ademais, essa não é uma exclusividade chilena. De acordo com o Padrão de Especialização de Exportações de 2014, o índice de exportação das principais economias latino-americanas - Argentina, Brasil, Chile e México - demonstra uma alta da desindustrialização que permanece até os dias atuais. Enquanto isso, desde a década de 1970, os países desenvolvidos membros da OCDE tiveram um crescimento anual de $2 \%$, enquanto os da América Latina oscilaram próximo ao 0,6\% ao ano (NETO, 2016). Tais números são indicativos de que os novos moldes neoliberais exportados para a periferia consolidam e reforçam desigualdades estruturais dentro do Sistema Internacional, fortalecendo os países do centro (MACHADO, 1999).

Desse modo, os governos neoliberais são comumente representados por um poder autoritário que deixa de procurar a ampliação do mercado interno, o pleno emprego e a universalização dos acessos aos serviços de saúde, educação e aposentadoria, "isentando o fisco de suas obrigações, transferindo-as para as famílias, enquanto multiplicam as oportunidades de negócios privados da elite" (IBARRA, 2011, p. 242). Na América Latina,

10 Outro exemplo digno de nota é o da Argentina. No país, entre 1990 a 2014, a participação dos produtos primários nas exportações aumentou de 44\% para 48,13\%, segundo levantamento do Programa de Análises da Dinâmica Industrial (PADI) da CEPAL (NETO, 2016). 
descontentamentos nessa linha muitas vezes levaram a importantes movimentos de protesto social.

\section{O Fim do Neoliberalismo? Chile e as Insurreições Sociais de 2019}

A expressão que dá título a este trabalho, "El Neoliberalismo nace y muere en Chile" (O Neoliberalismo Nasce e Morre no Chile), foi utilizada como frase de efeito nas diversas manifestações, levantes e protestos ocorridos no Chile em 2019. Se o neoliberalismo começou no Chile como um laboratório do que daria certo ou não no que tange à implementação de políticas econômicas e sociais, as manifestações de 2019 trazem a possibilidade de um novo paradigma: o neoliberalismo poderia, assim como nasceu, morrer no Chile.

As insurreições sociais chilenas foram resultantes de um descontentamento acumulado pela população ao longo de décadas de implementação do neoliberalismo no país. O estopim se deu após a autorização do governo de Sebastián Piñera a aumentar em 30 pesos a tarifa máxima do metrô de Santiago, capital do país. Diante disso, centenas de pessoas membros de movimentos estudantis começaram a pular as catracas do metrô como atos de resistência coletiva (MARTINS, 2019). No entanto, o movimento do "pula-catraca" foi apenas o gatilho para o início de uma insurreição social, tendo em vista que já havia em curso um processo de insatisfação generalizada. As demonstrações, iniciadas no dia 14 de Outubro de 2019 foram marcadas pelo protagonismo de jovens, principalmente de movimentos secundaristas, mas logo em seguida somaram-se aliados de diversos setores: a principal reivindicação era uma Assembleia Constituinte, já que a Constituição em vigor atualmente havia sido elaborada durante a Ditadura de Pinochet (MARTINS, 2019).

O resultado inicial foi uma grande violência policial em represália aos movimentos: policiais fortemente armados, gás lacrimogêneo, jovens presos e até atropelados. Com efeito, as ações tomam um caráter mais violento: 16 estações de metrô e um edifício de energia são queimados em uma mesma noite por manifestantes, supermercados foram saqueados e barricadas foram instaladas nas ruas da capital (BBC, 2019; EL PAíS, 2019). Diante da rebelião, a polícia passa a não conseguir mais controlar as forças sociais, razão pela qual o governo declarou Estado de Emergência, definiu toque de recolher, restringiu o direito às manifestações e determinou a ocupação da cidade pelas Forças Armadas. O presidente Sebastian Piñera declarou guerra ao povo para conter as rebeliões (O ESTADO DE MINAS, 2019).

É importante ressaltar que houveram diversas violações de Direitos Humanos ao longo desse processo: 20 pessoas morreram, 584 ficaram feridas e mais de 9 mil pessoas foram presas, como resultados das repressões aos protestos (INDH, 2019). Após as movimentações incessantes nas ruas, houve uma paralisação nacional: uma greve de 48h 
iniciada em 23 de outubro, exigindo o cumprimento das principais pautas da insurreição: redução da jornada de trabalho; uma nova Constituinte; reforma tributária; reforma do sistema previdenciário; restauração dos serviços públicos essenciais. Em resposta, o presidente anunciou um conjunto de medidas chamado "Nova Agenda Social", atendendo a maior parte das reivindicações.

Além disso, o Governo Federal e o Congresso propuseram um plebiscito que seria realizado em abril de 2020 para decidir sobre a realização de uma nova Constituinte. No quadro atual, o Chile espera o referendo (adiado para outubro de 2020 em razão da pandemia do Covid-19) que decidirá ou não a elaboração da nova Constituição, um passo importante para os direitos sociais e serviços básicos que há anos estão sendo negados ao povo chileno (CAZARRÉ, 2020; INDH, 2019). A elaboração de uma nova Constituição poderia marcar uma ruptura com o sistema político anterior. Tendo em vista as insurreições sociais organizadas, decorrentes de um processo de profunda frustração com o sistema econômico social e político vigente que chacoalhou o Chile, seria esse o início do fim do 'sucesso' neoliberal na América Latina?

\section{Considerações Finais}

O principal objetivo deste artigo foi entender como o viés desestatizante do projeto de economia neoliberal implementado no Chile a partir da década de 1970 ocasionou em uma crise econômica e política no país. Buscou-se também relacionar tal crise com as insurreições sociais de 2019 anunciando um possível fim do paradigma neoliberal no Chile. Para esta análise, utilizamos como arcabouço teórico a Teoria do Sistema Mundo, de Immanuel Wallerstein, e algumas abordagens teóricas variadas das Relações Internacionais, como a Teoria do Poder Global e o conceito de Hegemonia.

No que diz respeito às conclusões deste trabalho, a pesquisa permitiu que verificássemos a relação de centro-periferia existente no Sistema Internacional, sobretudo, no que diz respeito aos Estados Unidos e ao Chile. Essa relação se mostra desigual e hierárquica, tendo em vista o vínculo de dependência do Chile enquanto periferia em relação ao centro. Compreendemos, através dos dados analisados comparativamente entre o governo social-democrata de Salvador Allende (1970-1973) e a Ditadura neoliberal de Augusto Pinochet (1973-1990), como o Chile se tornou o laboratório do neoliberalismo, dirigindo-se desde então a uma crise social, econômica e política.

Assim, o presente trabalhou buscou responder à seguinte pergunta: como o projeto neoliberal instaurado no Chile, um país da periferia do Sistema Internacional impactou a economia, a política e a sociedade deste país, tornando-o dependente do centro? Analisando os dados qualitativos e quantitativos, podemos perceber que a adoção deste projeto e a 
consolidação da própria Ditadura também corresponde com a ascensão da escola econômica neoliberal nos Estados Unidos, sua exportação para a periferia e a narrativa de que tal projeto socioeconômico seria a solução para o problema de subdesenvolvimento da América Latina. Essa mesma lógica se manifesta na atuação das instituições financeiras internacionais, que demandam a adoção do pacote neoliberal como condicionante para a concessão de empréstimo, reforçando assim agendas econômicas originalmente tecidas pelo Departamento do Tesouro dos EUA. Dessa maneira, podemos afirmar que a adoção e a manutenção do neoliberalismo no Chile são estimuladas pelos Estados Unidos, hegemon da política internacional, não somente pelos ganhos materiais, que são abundantes, mas pelo acúmulo de poder normativo que é gerado nesta relação hierárquica.

O artigo também possibilitou uma análise sobre os resultados contemporâneos do neoliberalismo no Chile, considerando que este sistema continua vigente no país. Sendo assim, podemos observar altos custos dos serviços públicos, privatização de grande parte dos setores da vida civil, intensificação da pobreza, liquidação dos direitos sociais e intensa desigualdade de renda. Diante disso, foi possível questionar os números macroeconômicos que apontavam o país como o "oásis latino-americano"11, tendo em vista que a riqueza representada pelo PIB, renda per capita e outros instrumentos não refletem a qualidade de vida encarada pela maioria das pessoas no país.

Por fim, este trabalho viabilizou a reflexão sobre as insurreições sociais que abalaram o Chile no fim de 2019. Estas, apesar de atualmente paralisadas pela pandemia do COVID19, demonstraram a alta insatisfação do povo chileno com o neoliberalismo, e levantaram possibilidades de uma nova ordem na periferia do Sistema: uma que não seja a de liquidação dos direitos fundamentais da sociedade em prol do mercado e das potências do centro capitalista, como até então ocorria sob o projeto neoliberal.

\section{Referências Bibliográficas}

ANTUNES, Ricardo. A desertificação neoliberal no Brasil (Collor, FHC e Lula). Editora Associados, São Paulo, 2004.

AMARAL, Marisa Silva. A Investida Neoliberal na América Latina e as Novas

Determinações da Dependência. Dissertação (Mestrado em Economia) - Instituto de Economia, Universidade Federal de Uberlândia. Uberlândia, 2006

AYERBE, Luis Fernando. Estados Unidos e América Latina: a construção da hegemonia. Editora UNESP, São Paulo, 2002.

\footnotetext{
11 Expressão utilizada pelo presidente chileno, Sebastián Piñera, para designar o Chile, em meio aos protestos contra o neoliberalismo no país, em 2019.
} 
BARDER, Alexander. American Hegemony Comes Home: The Chilean Laboratory and the Neoliberalization of the United States. Alternatives: Global, Local, Political, 38(2), p. 103121, 2013.

BATISTA, Paulo. O Consenso de Washington: A Visão Neoliberal Dos Problemas Latino-Americanos. Pensando o Brasil, Editora FUNAG, São Paulo, 1994.

BBC NEWS BRASIL. Como a Escola de Chicago transformou o Chile em laboratório do neoliberalismo. Disponível em:

$<$ https://economia.uol.com.br/noticias/bbc/2019/03/23/bolsonaro-no-chile-como-a-escola-dechicago-transformou-pais-latino-americano-em-laboratorio-do-neoliberalismo.htm>. Acesso em: 14.jun.2020.

BBC NEWS MUNDO. Protestas en Chile: la histórica marcha de más de un millón de personas que tomó las calles de Santiago. Disponível em:

<https://www.bbc.com/mundo/noticias-america-latina-50190029>. Acesso em:12.mai.2021.

BERNAL-MEZA, Raúl. As relações entre Argentina, Brasil, Chile e Estados Unidos: política exterior e Mercosul. Revista Brasileira de Política Internacional, v. 41 (1): 90-108, 1998.

BRESSER-PEREIRA, Luiz Carlos. A Crise Financeira Global e Depois: um novo capitalismo? Revista Novos Estudos, v. 86, 2010.

BELLUZZO, Luiz Gonzaga; TAVARES, Maria da Conceição. Uma reflexão sobre a natureza da inflação contemporânea. In: XII Reunião Anual da ANPEC. Rio de Janeiro, 1985.

CAZARRÉ, Marieta. Chile adia plebiscito para mudar Constituição devido ao Coronavírus. AGÊNCIA BRASIL, 2020. Disponível em:

$<$ https://agenciabrasil.ebc.com.br/internacional/noticia/2020-03/chile-adia-plebiscito-paramudar-constituicao-devido-ao-coronavirus>. Acesso em 22 mai. 2020.

CONJUNTURA ECONÔMICA: Chile, duas décadas de política econômica. Rio de Janeiro: Fundação Getúlio Vargas v. 42, n. 9, set. 1988.

CORVALÁN, Luis. El Gobierno De Salvador Allende. Lom Ediciones, Santiago, Chile, 2003.

COX, Robert W. Gramsci, hegemonia e relações internacionais: um ensaio sobre o método. In: GILL, S. (Org.). Gramsci, materialismo histórico e relações internacionais.

Rio de Janeiro: Editora UFRJ, 2007. p. 101-123

DAVIS, Nathaniel. Os Dois Últimos Anos de Salvador Allende. Editora Civilização Brasileira, Rio de Janeiro, 1990.

DESTRADI, Sandra. Regional powers and their strategies: empire, hegemony, and leadership. Review of International Studies, Vol. 36, No., p. 903-930, 2010.

DOS SANTOS, Theotônio. A teoria da dependência: um balanço histórico e teórico. Editora Civilização Brasileira. Rio de Janeiro, 2000.

DUMÉNIL, Gérard; LÉVY, Dominique. Neoliberalismo - Neo-imperialismo. Revista Economia e Sociedade, v.16, n.1 (29), p.1-19, 2007.

DUMÉNIL, Gérard; LÉVY, Dominique. The Crisis of Neoliberalism. Massachusetts: Harvard 
University Press, 2011.

EL PAÍS. Siete claves para entender lo que ocurre en Chile. Disponível em: $<$ https://www.elpais.com.uy/mundo/siete-claves-entender-ocurre-chile.html>. Acesso em: 14.jun.2020.

ENCINA, Carlos. O conflito social no Chile: Estado, mercado e democracia. Revista Plural, v. 22(1), 53-65, São Paulo, 2015.

FIORI, José Luís. O poder global e a nova geopolítica das nações. Crítica y Emancipación, v. 1, n. 2, p. 157-183, 2009.

FLEURY, Sonia. Políticas sociais e democratização do poder local. Revista de Administração Municipal, v. ano 49, p. 39-48, 2004.

FOUCAULT, Michel. O Nascimento da Biopolítica. Editora Martins Fontes, São Paulo, 2008.

FFRENCH-DAVIS, Ricardo. Chile entre el neoliberalismo y el crecimiento con equidad. 4 ed. Santiago: J. C. Sáez Editor, 2008.

FUNDAÇÃO SOL. GASTO EN SALUD CHILE - OCDE. Disponível em:

$<$ http://www.fundacionsol.cl/graficos/gasto-en-salud-chile-ocde/>. Acesso em: 14.jun.2020.

FUNDAÇÃO SOL. Un $26 \%$ de los chilenos son morosos y contraen nuevas deudas para pagar anteriores. Disponível em: <http://www.fundacionsol.cl/2019/08/un-26-de-los-chilenosson-morosos-y-contraen-nuevas-deudas-para-pagar-anteriores/>. Acesso em: 14.jun.2020.

GARCIA, Ana. Hegemonia e Imperialismo: Caracterizações da Ordem Mundial Capitalista após a Segunda Guerra Mundial. Revista Contexto Internacional. Rio de Janeiro, vol. 32, n. 1, p. 155-177, 2010.

GRAMSCI, Antonio. Cadernos do Cárcere. Volume 1. Rio de Janeiro, Editora Civilização Brasileira, 1999.

IBARRA, David. O neoliberalismo na América Latina. Revista de Economia Política, vol. 31, no 2 (122), p. 238-248, 2011. Disponível em: <https://www.scielo.br/pdf/rep/v31n2/04. the pdf>. Acesso em: 9 mai.2020.

INDH Chile. INDH califica violaciones a los DDHH como "graves y múltiples" y crítica "excesiva demora" de Carabineros en tomar medidas para evitar nuevas vulneraciones. Chile, 2019. Disponível em: <https://www.indh.cl/indh-califica-violaciones-a-los-ddhh-comograves-y-multiples-y-critica-excesiva-demora-de-carabineros-en-tomar-medidas-para-evitarnuevas-vulneraciones/>. Acesso em: 15.jun.2020.

KREMERMAN, Marco; PÁEZ, Alexander; SÁEZ, Benjamín. Endeudar para gobernar y mercantilizar: El caso del CAE (2020). Fundación SOL, Chile, 2020. Disponível em: <http://www.fundacionsol.cl/wp-content/uploads/2020/05/CAE2020-1.pdf>. Acesso em: 15.jun.2020.

LIRA, Francisco. Do socialismo ao neoliberalismo: o Chile dos anos 1970. Revista de Economia Política, vol. 31, p. 238-248, 2011.

MACHADO, Luiz Toledo. A teoria da dependência na América Latina. Estudos Avançados, v. 13, n. 35, p.199-215, 1999. 
MARTINS, Antonio. Aconteceu em Santiago. OUTRAS PALAVRAS, 2019. Disponível em: $<$ https://outraspalavras.net/movimentoserebeldias/aconteceu-em-santiago/>. Acesso em: 22 mai.2020.

MARTINS, José Ricardo. Immanuel Wallerstein e o sistema-mundo: uma teoria ainda atual? Revista Iberoamérica Social, revista-red de estudios sociales (V), pp. 95-108. Rio Grande do Sul, 2015.

MARX, Karl. O Capital. Livro 3. 2.ed. Trad. Wenceslao Roces. México: Fondo de Cultura Económica, 1968.

MOREL, Blanca Lila. O desenvolvimento do Chile das reformas econômicas de 1973 a 2006. Pontifícia Universidade Católica do Rio Grande do Sul (Faculdade de Administração, Contabilidade e Economia), Mestrado em Economia, Dissertação de Mestrado, 2008.

NASCIMENTO, Priscila. O neoliberalismo no México e a emergência do movimento zapatista. Marília, Universidade Estadual Paulista, São Paulo, 2008.

NETO, Antonio. Desindustrialização prematura na América Latina? Uma breve análise. Revista Temas de economia aplicada. Fundação Instituto de Pesquisas Econômicas, n.425, p. 34-46. São Paulo, 2016.

NYE, Joseph S. Paradoxo do Poder Americano. São Paulo: Editora UNESP, 2002.

O ESTADO DE MINAS. Cronologia dos Distúrbios Sociais no Chile. 2019. Disponível em: <https://www.em.com.br/app/noticia/internacional/2019/10/25/interna_internacional,1095824/cr onologia-dos-disturbios-sociais-no-chile.shtml> Acesso em: 21 mai. 2020.

ORGANIZAÇÃO DAS NAÇÕES UNIDAS. Relatório do Desenvolvimento Humano 2019 Além do rendimento, além das médias, além do presente: Desigualdades no desenvolvimento humano no século XXI. Programa das Nações Unidas para o Desenvolvimento (PNUD), 2019.

OREIRO, José Luis; FEIJÓ, Carmem A. Desindustrialização: conceituação, causas, efeitos e o caso brasileiro. Revista de Economia Política, v. 30, n. 2, p. 219-232, 2010.

OSÓRIO, Jaime. Crítica de la Economía Vulgar: Reproducción del Capital y Dependencia. México: Grupo Editorial Miguel Angel Porrúa, 2004.

PALMA, Gabriel. The revenge of the market on the rentiers. Why neo-liberal reports of the end of history turned out to be premature. Cambridge Journal of Economics, v. 33, p. 829-69, 2009.

PEREIRA, Alexsandro Eugenio. Três perspectivas sobre a política externa dos Estados Unidos: poder, dominação e hegemonia. Rev. Sociologia. Política, v. 19, n. 39, p. 237-257, Curitiba, 2011.

ROWTHORN, Robert; RAMASWAMY, Ramana. Growth, Trade and Deindustrialization. IMF Staff Papers, v. 46, n. 1, 1999.

SANTOS, Milton. Por uma outra globalização: do pensamento único à consciência universal. Rio de Janeiro: Record, 2001. 
y telecomunicaciones. México: Plaza y Valdés-UOM-ENAT, 2004.

TRIEPEL, Heinrich. Die Hegemonie. Ein Buch von führenden Staaten. Stuttgart: Kohlhammer, 1938.

VALDÉZ, Juan Gabriel. Pinochet's Economists: The Chicago School in Chile. Cambridge: Cambridge University Press, 1995.

VALOIS, Felipe. O capital especulativo e seus efeitos sobre a economia brasileira. Trabalho de Conclusão de Curso em Administração, Universidade Federal de Sergipe, Rio de Janeiro, 2018.

VASCONCELOS, Joana. Reforma agrária e socialismo na América Latina: Cuba e Chile. Agrarismos: Estudos de História e Sociologia do Mundo Rural Contemporâneo, Editora Mauad X, Rio de Janeiro, 2017.

WALLERSTEIN, Immanuel. O sistema mundial moderno. Vol. I: a agricultura capitalista e as origens da economia-mundo europeia no século XVI. Porto: Ed. Afrontamentos, 1974.

WISECARVER, Daniel. EI modelo económico chileno. Editora UCC, Santiago ,Chile, 1992

WORLD BANK. World Development Report. Washington, 1990. 